\title{
Settlement Analysis of Treated Soft Clay using LECA Replacement through Numerical Modelling
}

\begin{abstract}
A. Zukri Malaysia. was then validated using developed Settlement Prediction Model, analytical equations, and numerical analysis. Another finding from this study is a decrease in the magnitude of the settlement as the internal friction angle of LECA increases.
\end{abstract}

Department of Civil Engineering, College of Engineering, Universiti Malaysia Pahang, Lebuhraya Tun Razak, 26300 Gambang, Kuantan, Pahang,
ARTICLE HISTORY

Received: 29th June 2021

Revised: $20^{\text {th }}$ Sept 2021

Accepted: $29^{\text {th }}$ Sept 2021

\section{KEYWORDS}

Soft soil

Soil replacement

Numerical modelling

Settlement

Lightweight aggregate

\section{INTRODUCTION}

Replacement methods are categorized as the easiest and oldest way of repairing soft soil under shallow foundations by replacing poor soil thus, minimizing the settlement problem [1]. The technique means by taking or removing the unwanted problematic part of soils and replacing it with other efficient materials such as gravel, sand and stone aggregates. However, in this study, LECA is use as alternative material instead of common aggregates. LECA is named by Lightweight Expanded Clay Aggregate are in category of a group lightweight aggregates (LWA) which has a relatively lower density than ordinary aggregates. Their characteristics, light, strong and yet sustainable to the environment make LECA as one of flexible material in construction. In worldwide application, LECA has successfully been introduced as medium in soil replacement method however not in Malaysia due to availability of the material. However, LECA aggregates have great potential to be produced in Malaysia due to the high availability of raw materials. Therefore, this study was conducted to highlight the use of LECA in soft soil replacement applications to increase the rate of settlement.

Replacement is most applicable and economically at time commonly used in soft cohesive soils as other soils [2]. The benefits of this method are it is simple to conducted compared to other method, need no advance machineries or equipment and can be performed by most general contractors. Soil replacement can become another option for the use of deep foundation since it is much more economic viability for the low-income population. The methods can be done either totally or partially replaced by a layer of stronger soils as long as the purposes of weak and low strength in sustaining high superstructure stresses can be overcome [3].

Many studies have been conducted to investigate the performances of LECA used in structural and geotechnical application. LECA consists of small, lightweight, bloated particles of burnt clay. Sonia and Subashini [4] claims that the thousands of small, air-filled cavities give LECA its strength and thermal insulation properties meanwhile, Zukri and Nazir [5] explain that lightweight aggregates exhibit considerable differences in particle shape, texture and properties, depending on the source and its method of production $[4,5]$.

\section{RELATED WORK}

Abbas [2] use soil replacement and sand piles to improve the soft soils underneath the shallow foundations. Analyses using finite elements methods (PLAXIS 3D program) were done to assess the settlement of soft clay which improved by compacted sand layers and floating sand piles. For simulation by finite element models, the used materials of the soil were simulated by the standards of linear elastic-perfectly plastic Mohr-Coulomb theory and situation of soil replacement, settlement values from the software were compared to Janbu's equations. The results from the PLAXIS were compared with results of Brom's analytical techniques and the obtained results demonstrated that the stress-settlement behaviour increases with increasing the thickness of replaced layer and also it increases with increasing the number of sand columns [2]. 
Gabr [3] in his study had use laboratory experiment as his main approaches in research study while numerical modelling as a verification process to determine the uncertainties of using replacement soil in controlling the settlement. The numerical work was carried out in three-dimensions using the software PLAXIS meanwhile Mohr-Coulomb failure mode was chosen for soil behaviour. The findings from his study resulted that the use of replacement soil can reduce settlement and construction cost considerably [3].

Meanwhile, the study of ECS used as embankment fill material was performed by Saride et al. [6]. A series of laboratory experiment on fill material, field monitoring and numerical analyses using PLAXIS 2D are performed to evaluate the settlement behaviour of embankment on soft clay. The design charts were proposed for the construction of lightweight fill embankment using Expanded Clay and Shale (ECS) material and can be used as a reference for embankment design [6]. The research clearly demonstrated that the use of lightweight ECS effectively reduced the approach of slab settlements. Field monitoring data of the Control and ECS test sections shows that the settlements reduced by $65 \%$ with the use of ECS fills. Finite element modelling (FEM) also showed a good match between predicted and monitored settlement time profiles. In addition, FEM analyses were conducted for various hypothetical embankment configurations and these results are used to develop design charts for the selection of ECS fills for embankment applications.

Prediction model has been developed by Zukri [7] to estimate the settlement magnitude of treated soft clay using LECA aggregates. The model is a design chart that can be referred to as early estimation of settlement ratio according to the thickness of replacement. The prediction model was developed under three different loading intensities. The settlement magnitude then can be calculated using relationship between settlement ratio and untreated settlement. The improvement performance of soft soil treated with LECA replacement is presented in terms of settlement ratio $(\eta)$, which is the ratio of treated $(S)$ to untreated $\left(S_{u}\right)$ condition. The prediction model has been successfully validated through physical modelling established in laboratory [7].

Overall, least studies are conducted on the settlement evaluation of soft soil treated with LECA replacement. Most of the researches focused on the improvement of treated soft soil in term of bearing capacity and settlement using natural aggregates and others type of lightweight material, mostly form recycle materials such as tyre chip, crush concrete and so on. Previously, Zukri [7] conducted numerical study on the settlement prediction of treated soft clay with LECA replacement method based on three different loading intensities under various thickness of replacement. However, the study was conducted under the same friction angle, i.e. $35^{\circ}$. Typically, different friction angles are contributed from specific density and modulus values. Therefore, this study is conducted in order to analyse the settlement magnitude of treated soft soils with LECA replacement method by respecting to the three majors parametric of; $50 \mathrm{kN} / \mathrm{m}^{2}, 100 \mathrm{kN} / \mathrm{m}^{2}$ and $150 \mathrm{kN} / \mathrm{m}^{2}$ of load intensity; $1.5 \mathrm{~m}, 2.5 \mathrm{~m}$ and $3.5 \mathrm{~m}$ raft thickness together with the friction angle of $\phi=35^{\circ}, \phi=37^{\circ}$, $\phi=40^{\circ}$ and $\phi=45^{\circ}$, where the study was performed by using PLAXIS $2 \mathrm{D}$ commercial software. This study was conducted in addition to previous studies conducted by [8].

\section{Objectives of the study}

The aim of this study is to evaluate the settlement behaviour of soft soil and how the soft soil interacts due to LECA replacement through two-dimensional numerical modelling. The relationship in settlement behaviour of soft soil treated with LECA replacement has been proposed under the various load intensities, raft thicknesses and LECA friction angles. The relationship developed in this study then will be validated using previous method established to predict the settlement of LECA raft.

\section{METHODOLOGY}

Numerical modelling is used as main approaches to determine the settlement of soft clay under specify load. A twodimensional analysis is used in this study with the help of PLAXIS 2D commercial software. The software provides finite element program that can be applied for all types of soil with user-friendly interface. Constitutive models range from simple linear to advance highly nonlinear models through which soil behaviour can be simulated. It is well proven and robust calculation procedures ensure converging calculations and accurate results. The selection of an effective constitutive model to reflect the real soft soil actions is not easy, because soils are complicated resources consisting of soil particles and voids filled with water and/or air. Therefore, it is very important to use an accurate soil model while conducting the study so that the results produced can identify the actual action of the soil.

The comparison has been made in this study by selecting the famous constitutive model to analyse the soft soil settlement under several selected conditions. The selection of model is based on availability of soft soil and LECA parameters. While the non-existent parameters were calculated based on correlation or indirectly calculated using other available parameters. The results obtained from the analysis were compared to analytical calculation. One dimensional Terzaghi's Equation has been used to calculate the settlement magnitude. The models selected for analyses are; MohrCoulomb Model (MC), Soft Soil Model (SS), Hardening Soil Model (HSM) and Soft Soil Creep Model (SSC).

The untreated condition was selected as a comparison model. For untreated soil, the settlement magnitude calculated was $186 \mathrm{~mm}$ (for $50 \mathrm{kN} / \mathrm{m}^{2}$ uniform load) while numerical result provided a slightly higher result, as predicted by SSM, HSM and SSC model. Compare to other models, MC model estimated close values, whereas almost equal to the analytical value $(151.17 \mathrm{~mm})$ where the percentage was less than $20 \%$. Similar to treated soil with $1.5 \mathrm{~m}$ and $2.5 \mathrm{~m}$ thickness LECA raft thickness, the settlement magnitude calculated using analytical method and value recorded from PLAXIS 2D seem 
to be close where the percentage was less than $20 \%$. From the justification made, the MC model is more dominant because the percentage of errors is lower than other models. Therefore, both LECA and soft soils are represented by Mohr Coulomb (MC) model with drained type. The other reasons for using MC models are because it is considered simple model to be used and fast computation due to constant stiffness assumption and soil is modelled as linear elastic perfectly plastic material and also has been adopted by many researchers due to model simplicity.

Drained analysis was chosen in this study to simulate long -term behavior and provide more sensitivity and parametric studies to be performed with less computational of time. Three (3) stages of calculation involve; Initial Phase; Phase 1 and Phase 2 with Plastic types of analysis were used in this study. Finite element analyses were conducted on LECA raft to determine the final settlement magnitude $(S)$ of treated soft clay. The location of the selected node is taken in the middle of the soil model which is about $10 \mathrm{~m}$ from the left and $5 \mathrm{~m}$ from the top, as the maximum settlement usually occurs in the centre. Since this study focuses on settlement analysis under a large loaded area and the modelling process is done in two dimensions, the results do not seem to be affected by boundary conditions. Other assumptions and limitations made in this study are as follows:

i. The effect caused by disturbance on the surrounding soil due to the construction process is neglected. Therefore, strength reduction factor $\left(\mathrm{R}_{\text {inter }}\right)$ is assumed to be 1 .

ii. The value of dilation angle can be estimated as $\psi=\varphi-30^{\circ}[9]$.

iii. In the subsequent FEM and analytical analyses, the settlement behavior of various LECA raft thickness is examined for $50 \mathrm{kN} / \mathrm{m}^{2}, 100 \mathrm{kN} / \mathrm{m}^{2}$ and $150 \mathrm{kN} / \mathrm{m}^{2}$. A vertical pressure is imposed on the raft, as a uniformly distributed load.

iv. The granular raft is assumed as a rigid smooth layer through which the uniform load is applied, where rigid plate is assigned as a medium for load transfer to the above ground.

v. The empirical correlation for LECA density, stiffness value and angle of friction are developed based on the available data of LECA properties. The correlation need to be made in order to increase the accuracy of the analysis results.

vi. Depth of soft soil utilized in this study is 10 meters and water table is assumed to be at ground surface.

\section{Parametric analysis}

From the review made, there are numerous of LECA manufacturer all around the world and the properties of the LECA are varies accordingly to their manufacturer's production. The friction angle values vary from $35^{\circ}$ to $53^{\circ}$ and the unit weight of LECA varied between $3 \mathrm{kN} / \mathrm{m}^{3}$ to $10 \mathrm{kN} / \mathrm{m}^{3}$, which is lower than water density [10]. The LECA raft with different thickness $(1.5 \mathrm{~m}, 2.5 \mathrm{~m}$ and $3.5 \mathrm{~m})$ for each load of $50 \mathrm{kN} / \mathrm{m}^{2}, 100 \mathrm{kN} / \mathrm{m}^{2}$ and $150 \mathrm{kN} / \mathrm{m}^{2}$ will be applied to the soft soil to determine the settlement magnitude. Four (4) different LECA friction angles of $35^{\circ}, 37^{\circ}, 40^{\circ}$, and $45^{\circ}$ were selected according to others available properties used in the analysis. The properties such as density and young modulus are also assessed based on their relation to the friction angle of the LECA material. Figure 1 below shows the schematic diagram of the replacement models applied in this study, while Figure 2 is the PLAXIS interface for the LECA replacement model. Table 1 represents the material properties used in the numerical modelling.

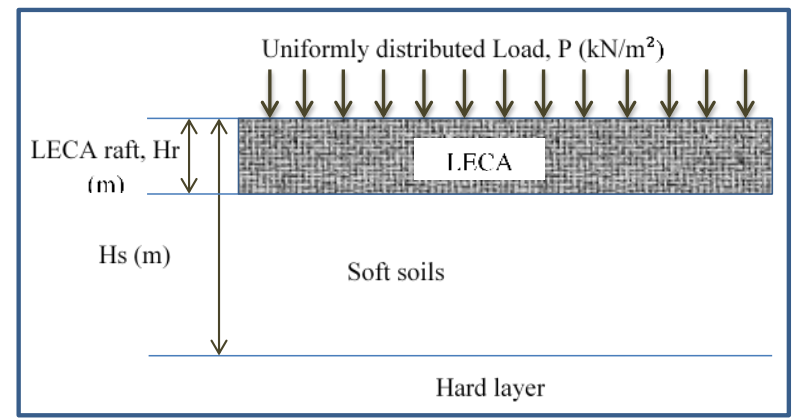

Figure 1. Schematic Diagram of LECA replacement model 


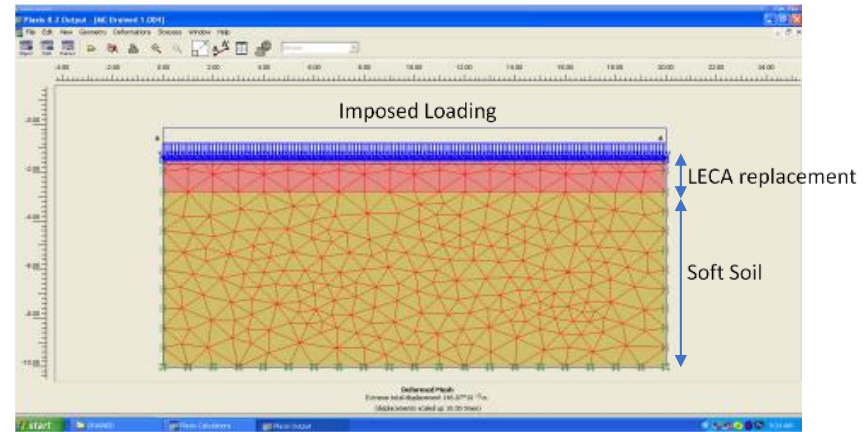

Figure 2. LECA replacement model (PLAXIS)

Table 1. Materials Properties used in the Numerical Analysis

\begin{tabular}{|c|c|c|c|c|c|}
\hline Parameter & Soft clay & \multicolumn{4}{|c|}{ LECA } \\
\hline Constitutive model & \multicolumn{5}{|c|}{ Mohr Coulomb } \\
\hline Type of analysis & \multicolumn{5}{|c|}{ Drained } \\
\hline Unit weight, $\gamma\left(\mathrm{kN} / \mathrm{m}^{3}\right)$ & 16.0 & 3.0 & 3.5 & 4.5 & 8.0 \\
\hline Permeability, k (m/day) & $2.229 \mathrm{X}(10)^{-5}$ & 2185.92 & 2185.92 & 2185.92 & 2185.92 \\
\hline Young's Modulus, E (kN/m²) & 2420 & 3132 & 3930 & 5353 & 8497 \\
\hline Cohesion, $c^{\prime}\left(k N / m^{2}\right)$ & 7 & 0 & 0 & 0 & 0 \\
\hline Poisson's ratio, $v$ & 0.30 & 0.30 & 0.30 & 0.30 & 0.30 \\
\hline Friction angle, $\phi^{\prime}\left({ }^{0}\right)$ & $25^{0}$ & $35^{0}$ & $37^{0}$ & $40^{\circ}$ & $45^{0}$ \\
\hline Dilatation angle, $\psi\left(\left(^{0}\right)\right.$ & 0 & $5^{0}$ & $7^{0}$ & $10^{\circ}$ & $15^{0}$ \\
\hline
\end{tabular}

\section{Method of Results Validation}

The settlement prediction graph developed in this study can be referred by engineers to evaluate the consolidation settlement of soft soil treated with LECA replacement. The procedure proposed by Zukri (2019) has been adopted to calculate the settlement magnitude under large-loaded area by referring to the developed design graph in this study. The chart reliability is then validated using three methods, i.e;

i. $\quad$ Prediction Model established for soft soil replacement using LECA material [7]. The Settlement Prediction Model is under Copyright IP_CR-2019_0349.

ii. Validate using analytical method proposed by Terzaghi, which is one dimensional consolidation equation according to several design conditions.

iii. Validate using 2D numerical analysis using PLAXIS commercial software according to same design conditions.

\section{Correlation of Friction angles, Density and Young Modulus}

Based on the various properties of LECA available all around the world, friction angle of LECA varies from $35^{\circ}$ to $53^{\circ}$ and their density depends on the gradation of the materials [11]. Since this study focused on four (4) friction angles $\left(\phi^{\prime}=35^{\circ}, \phi^{\prime}=37^{\circ}, \phi^{\prime}=40^{\circ}\right.$ and $\left.\phi^{\prime}=45^{\circ}\right)$, therefore empirical correlation is needed to conduct as to predict the appropriate Unit Weight and Young Modulus of LECA according to the selected friction angle selected in this study. Figure 3 below shows the plot of correlation between friction angles and density of LECA. The plot however valid for LECA with density of $2 \mathrm{kN} / \mathrm{m}^{3}$ until $10 \mathrm{kN} / \mathrm{m}^{3}$ which the values are still within the range of LECA density.

The smooth correlation plot of density and particles density is later developed to defining Young Modulus, $E$ values. Figure 4 shows the plot of density against particle density of LECA aggregates. The plot was made based on the properties of LECA recorded through different fabricators around the world. The modulus value determined using this empirical correlation were in good agreement with previous finding, where the $E_{a}$ value of expanded clay were from $5.5 \mathrm{kN} / \mathrm{m}^{2}$ to $7.8 \mathrm{kN} / \mathrm{m}^{2}$ and the average was $6.8 \mathrm{kN} / \mathrm{m}^{2}$ and the variation stayed within $20 \%$ [12]. Then, the Young Modulus, E of LECA aggregates is calculated using equation proposed by Shafigh et al. [13]. 


\section{Internal friction angle VS LECA density}

(valid for $2 \mathrm{kN} / \mathrm{m}^{3}$ to $10 \mathrm{kN} / \mathrm{m}^{3}$ )

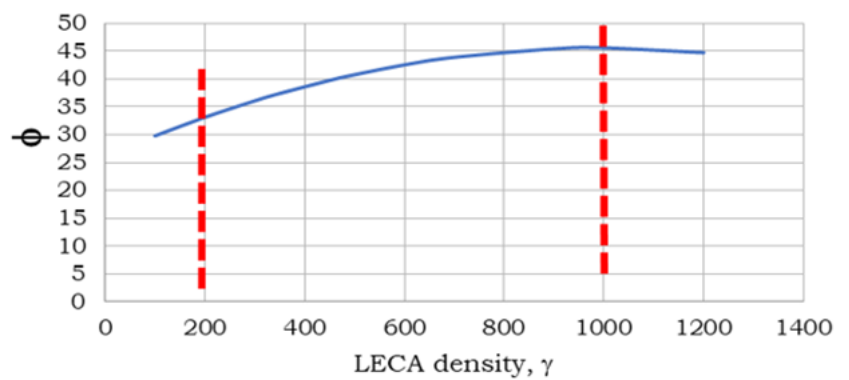

Figure 3. Empirical Correlation between Friction Angles and Density of LECA

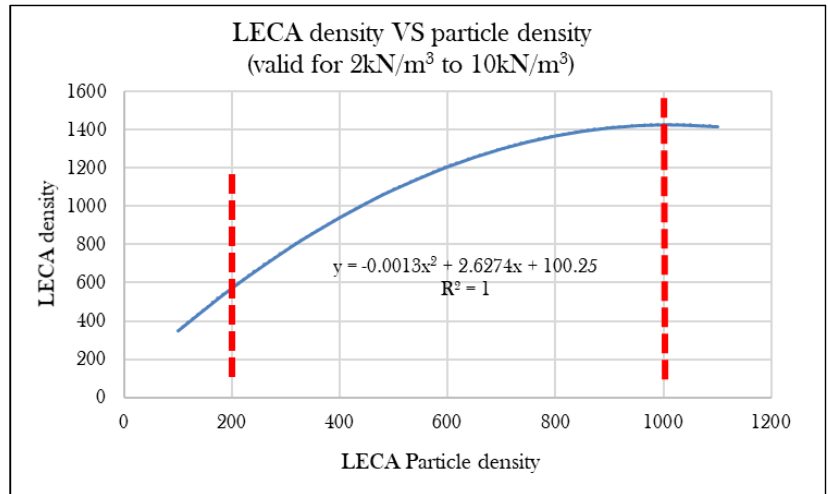

Figure 4. Empirical Correlation between Density and Particle Density

\section{ANALYSIS AND RESULTS}

The analysis was performed under three different loading intensity, three different thickness of LECA raft and four different angles of friction. Sixty models in total were developed to simulate the soft soil displacement using LECA as a replacement material. The results from the analysis is presented through three (3) settlement plot;

i. Settlement magnitude against LECA raft thickness

Figure 5 below show the plot of settlement magnitude against LECA raft thickness with respect to the friction angle of $40^{\circ}$. The plot shows almost linearly decrease of the settlement with the increasing of LECA raft thickness. In the overall, LECA with higher friction angle will exhibit higher density and stiffness modulus. Also, higher friction angle contributed to higher strength of aggregate material. The pattern is found to be similar to other LECA friction angle. The findings are in good agreement with previous study conducted, where the thickness of replacement contributed to better settlement improvement [1-3,14,15]. This has proven that lightweight materials such as LECA are as good as ordinary aggregates that can be used as replacement materials to strengthen the soft soil with limited depth.

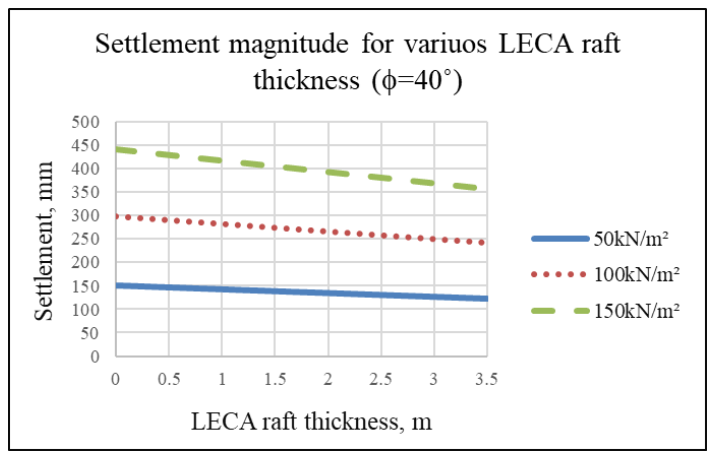

Figure 5. Settlement magnitude for various LECA raft thickness under

ii. Settlement magnitude against fiction angle

The graph of settlement magnitude for various friction angle of LECA under a uniform loading of $50 \mathrm{kN} / \mathrm{m}^{2}, 100 \mathrm{kN} / \mathrm{m}^{2}$ and $150 \mathrm{kN} / \mathrm{m}^{2}$ were plotted in Figure 6, Figure 7 and Figure 8, respectively. The plot shows that the settlement decreases linearly with increasing of LECA friction angle; in which the higher value of friction angle support greater density and 
stiffness modulus and thus increase the strength of the LECA itself. Comparatively in terms of settlement improvement factor, the results identified that the settlement improvement factor increased with increasing friction angle value. The results show that the percentage of improvement increase up to $11 \%, 18 \%$ and $25 \%$ for $1.5 \mathrm{~m}, 2.5 \mathrm{~m}$ and $3.5 \mathrm{~m}$ of LECA thickness under a loading intensity of $50 \mathrm{kN} / \mathrm{m}^{2}$ while both settlement magnitude under $100 \mathrm{kN} / \mathrm{m}^{2}$ and $150 \mathrm{kN} / \mathrm{m}^{2} \mathrm{loading}$ have a similar level of improvement.

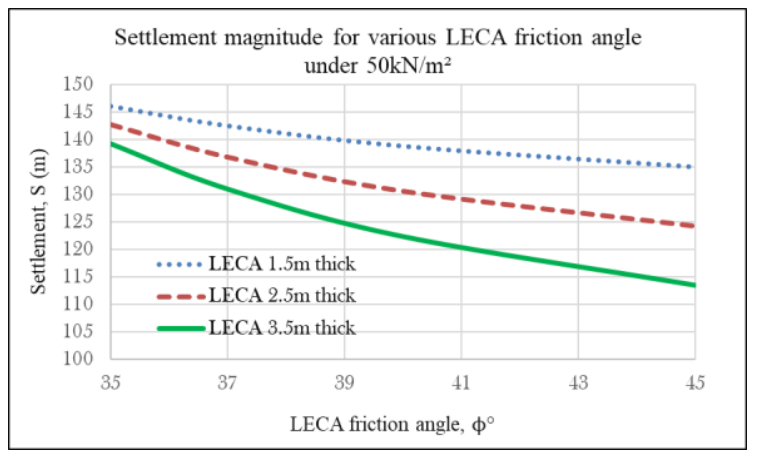

Figure 6. Settlement magnitude for various LECA friction angle under 50kN/m²

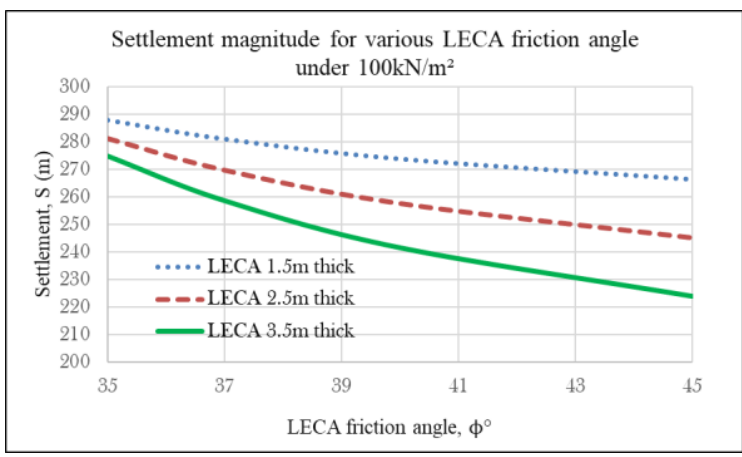

Figure 7. Settlement magnitude for various LECA friction angle under $100 \mathrm{kN} / \mathrm{m}^{2}$

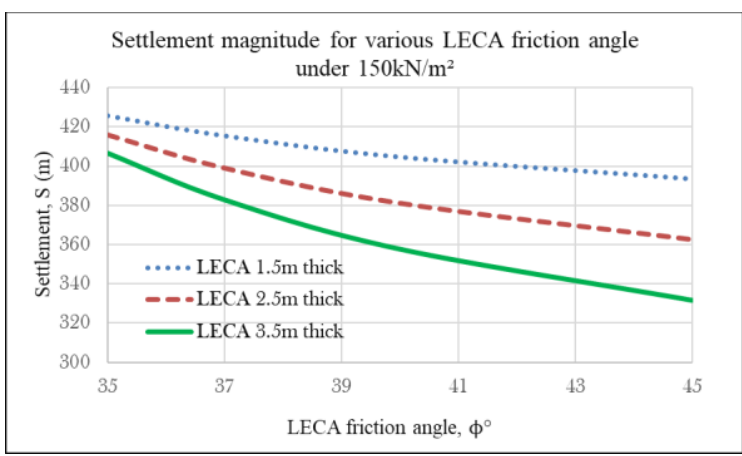

Figure 8. Settlement magnitude for various LECA friction angle under $150 \mathrm{kN} / \mathrm{m}^{2}$

\section{iii. Load-settlement curve}

The study also discovered the impact of uniformly distribution load to the settlement of the compacted LECA layers. Figure 9 show the load-settlement behaviour of improved soft clay by replacing $1.5 \mathrm{~m}$ of compacted LECA layers to the soft clay. The plot shows increasing of the settlement as the load intensity increases. The plot shows the highest settlement rate is recorded by LECA with $\phi=45^{\circ}$ where the settlement is $392.65 \mathrm{~mm}$ at $150 \mathrm{kN} / \mathrm{m}^{2}$ followed by $404.20 \mathrm{~mm}, 426.30 \mathrm{~mm}$ and $439.71 \mathrm{~mm}$ for $\phi=40, \phi=35$ and untreated soft soils, respectively. However, in terms of practicality LECA aggregate should not be used for load intensities greater than $130 \mathrm{kN} / \mathrm{m}^{2}$ due to particles crushing strength limitation [7]. In conclusion, the action of replacing the upper part of the soft soil layer with LECA aggregates provides a more uniformly distribution load on the raft and thus minimizing the settlement of soft soils. The curved pattern was found to be similar to the normal aggregate load solution plot. 


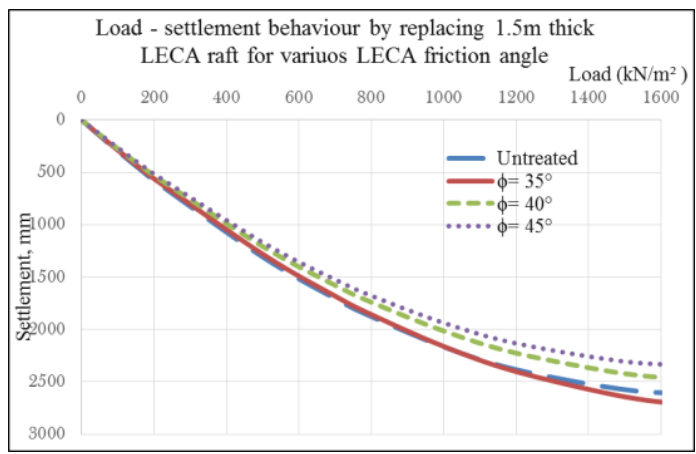

Figure 9. Load - Settlement Curve for 1.5 meter LECA Raft

\section{Settlement Prediction Chart}

Settlement ratio $(\eta)$ is used as to model the improvement factor of soft soil by using LECA replacement. The settlement ratio is taken by the ratio of the treated soft soil to the untreated. The relation of the settlement ratio $(\eta)$ with depth ratio $(\beta)$ is as shown in Figure 10 is plot by using Finite Element Method and parametric study, which the graph is also can be considered as the design chart to estimate the settlement ratio based on the depth of replacement. The chart do shows the same pattern with previous study conducted by [7], which the settlement ratio decrease with the increasing of depth ratio. The improvement of soft soil settlement by using LECA replacement is defined through the chart.

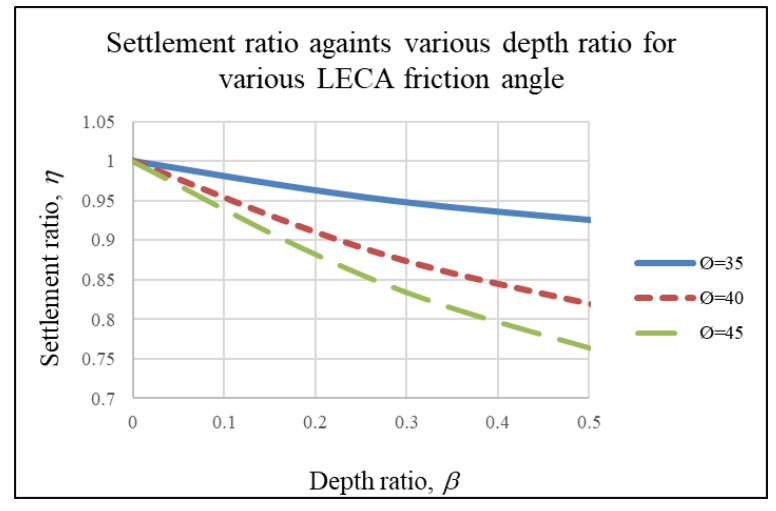

Figure 10. LECA Raft Design Chart

The procedures to do prediction of the settlement of LECA replacement are adopted from previous methods proposed by Zukri (2019), as follows;

i. Calculate the settlement of untreated ground using one-dimensional consolidation equation for normally consolidated clay soil, $S u$ by using Equation 1 or Equation 2 [16];

$$
\begin{gathered}
S_{u}=\frac{\Delta_{e}}{1+e_{0}} H_{s} \\
S_{u}=\frac{C_{c}}{1+e_{0}} H_{s} \log \frac{{\sigma_{0}^{\prime}+\Delta \sigma^{\prime}}_{\sigma_{0}^{\prime}}}{\sigma_{0}}
\end{gathered}
$$

ii. Obtain S/SU with specified $\beta$ value based on the information of Raft thickness, $H r$ and depth of soft soil, Hs from design chart in Figure 9;

$$
\beta=H_{r} /\left(H_{s}-H_{r}\right)
$$

iii. Compute the settlement, $\mathrm{S}$ of LECA raft using Equation 4;

$$
S=\eta x S_{u}
$$

\section{Design Chart Validation}

The design chart developed in this study has been succesfully validated using three different methods which the first is Settlement Prediction Model [7] and secondly by using one-dimensional analytical method proposed by Terzaghi; and lastly by using two-dimensional numerical analysis using PLAXIS software according to the same design conditions. 
Figure 11 illustrates the validation of this study in compare with other proposed method and in overall, the plot shows that the method developed in this study predicted well for settlement under $50 \mathrm{kN} / \mathrm{m}^{2}$ loading, where the magnitude calculated are closed to other previuos prediction method. Menwhile, for loading more than $50 \mathrm{kN} / \mathrm{m}^{2}$, the different are found to be within the acceptable range $(20 \%)$. As conclusion, the method established in this study is reliable to be use to predicted the settlement magnitude of soft soil treated with LECA repalcement.

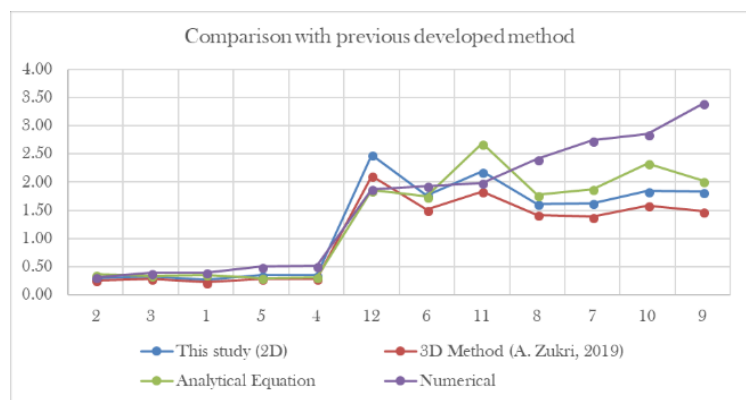

Figure 11. Comparison of this study with previous method

\section{CONCLUSION}

Throughout this study, analysis is done by using PLAXIS 2D software as to analyse the settlement magnitude of LECA replacement placed in the soft soil as to reduce the settlement. The findings conclude that the increase in friction angle of LECA had improved the strength of the LECA properties in which contributes to the decrease in settlement for all depth and load applied.

The relationship in settlement behaviour of soils relate with LECA replacement is defined by the design chart which were established by using numerical analysis in order to predict the long term of settlement magnitude under the large loaded area. The design chart is useful as to predict the early settlement ratio based on the depth of LECA replacement. In meantime, the design chart is considered as reliable since it is validated by using three (3) methods namely; (1) Settlement Prediction Model, (2) analytical method proposed by Terzaghi and (3) two-dimensional numerical analysis using PLAXIS software according to the same design conditions.

The study proved that the LECA replacement can improve the settlement of soft soils. However, for further study, it recommended that the study is include the application of geotextiles as the interfaces between the LECA and soft soils layer in order to increase the effectiveness of the LECA besides reduce the possibilities of buoyancy effect due to the increasing ground water table since the LECA particles are lighter compared to water. The geotextiles also can be medium of separator between soil and LECA material.

\section{REFERENCES}

[1] A. Zukri, R. Nazir, and N. K. Shien, "The Settlement Evaluation of Improved Soft Clay Using LECA Replacement Technique," in SEAGC2018, 2018, vol. 1, no. x.

[2] B. J. Abbas, "The Settlement Evaluation of Improved Soft Clay using Sand Columns and Partial Replacement Technique," Int. J. Eng. Res. Technol., vol. 5, no. 7, pp. 348-355, 2016.

[3] A. K. Gabr, "The Uncertainties of Using Replacement Soil in Controlling Settlement," J. Am. Sci. 2012, vol. 8, no. 12, pp. 662-666, 2012.

[4] T. Sonia and R. Subashini, "Experimental Investigation on Mechanical Properties of Lightweight Concrete using LECA and Steel Scraps," SSRG Int. J. Civ. Eng., vol. 5, no. 11, pp. 594-598, 2017.

[5] A. Zukri and R. Nazir, "The Sustainable Materials Used As Stone Column Filler: A Short Review," iCITES2018, 2018, doi: 10.1088/1757-899X/342/1/012001.

[6] S. Saride, A. J. Puppala, R. Williammee, and S. K. Sirigiripet, "Use of Lightweight ECS as a Fill Material to Control Approach Embankment Settlements," J. Mater. Civ. Eng., vol. 22, no. June, pp. 607-617, 2010, doi: 10.1061/(ASCE)MT.19435533.0000060 .

[7] A. Zukri, "Soft Clay Stabilisation Using Lightweight Aggregate for Column Matrices," UNIVERSITI TEKNOLOGI MALAYSIA, 2019.

[8] A. Zukri, R. Nazir, and K. S. Ng, "The Settlement Evaluation of Improved Soft Clay Using LECA Replacement Technique The Settlement Evaluation of Improved Soft Clay Using LECA Replacement Technique,” no. November, 2018.

[9] M. Kowalska, "Influence Of The Ratio Between Dilatancy Angle And Internal Friction Angle On Stress Distribution Behind A Gravity Retaining Wall," 2015.

[10] A. Zukri, R. Nazir, M. S. Khairun Nissa, and H. Moayedi, "Physical and Mechanical Properties of Lightweight Expanded Clay Aggregate ( LECA )," in MATEC Web of Conferences, 2018, vol. 01016.

[11] A. Zukri, R. Nazir, and H. Moayedi, "Physical Properties of Lightweight Expanded Clay Aggregate ( LECA )," in The 12th International Civil Engineering Post Graduate Conference (SEPKA) - The 3rd International Symposium on Expertise of Engineering Design (3rd ISEED) (SEPKA-ISEED 18), 2018. 
[12] H. J. Y. T. C. K. H. Chen, "Evaluating the Elastic Modulus of Lightweight Aggregate,” ACI Mater. J., vol. 100, pp. 108-113, 2003.

[13] P. Shafigh, H. Ghafari, H. Bin Mahmud, and M. Z. Jumaat, "A comparison study of the mechanical properties and drying shrinkage of oil palm shell and expanded clay lightweight aggregate concretes," Mater. Des., vol. 60, pp. 320-327, 2014, doi: http://dx.doi.org/10.1016/j.matdes.2014.04.001.

[14] M. Ornek, M. Laman, A. Yildiz, and A. Demir, "Numerical analysis of circular footings on natural clay stabilized with a granular fill," Acta Geotech. Slov., pp. 61-75, 2012.

[15] S. Abdel Salam, "The Effect of Replacement Soil on Reducing Settlement of Footing on Deep Soft Clay Using Numerical Approach," Cairo university, Giza, Egypt, 2007.

[16] B. M. Das, Principles of Geotechnical Engineering. 2010. 